\title{
Preoperative myocardial ischaemia: its relation to perioperative infarction
}

\author{
H YOUSIF, G DAVIES, S WESTABY,* O F PRENDIVILLE, $\quad R$ N SAPSFORD,* \\ C M OAKLEY \\ From the Departments of Medicine (Clinical Cardiology), * Surgery (Cardiothoracic Surgery) and $\dagger$ Chemical \\ Pathology, Royal Postgraduate Medical School and Hammersmith Hospital, London
}

SUMMARY One hundred consecutive patients undergoing coronary artery bypass surgery were randomly allocated to a preoperative $(24 \mathrm{~h})$ intravenous infusion of isosorbide dinitrate $(1.5-15 \mathrm{mg} / \mathrm{hr}$ ) (50 patients) or to placebo (50 patients). The characteristics of the two groups were similar. Evidence of acute myocardial ischaemia was sought by continuous electrocardiographic Holter recordings and acute myocardial infarction by the appearance of new $Q$ waves and increased activity of the creatine kinase $M B$ isoenzyme. Episodes of acute myocardial ischaemia were found in $18 \%$ of patients in the control group and in none of those who received isosorbide dinitrate. None the less, the frequency of perioperative myocardial infarction was similar $(22 \%$ and $18 \%$ respectively) in the two groups. Perioperative infarction was significantly more common in women, in patients with unstable angina or poor left ventricular function, in those who had coronary endarterectomy, and in those in whom the aortic clamping time was greater than 50 minutes. These factors may have obscured any effect that prevention of preoperative ischaemia had on perioperative infarction.

Preoperative infusion of isosorbide dinitrate eliminated preoperative ischaemia but did not influence the occurrence of perioperative infarction. The probable benefits of prevention of preoperative ischaemia on postoperative left ventricular function, which is a determinant of long term survival, remain to be established.

Myocardial infarction is a frequent complication of aortocoronary saphenous vein grafting and an important cause of perioperative death and long term morbidity. ${ }^{1-9}$ The frequency of infarction has been variously reported to be between $4 \%$ and $40 \%$, depending to a certain extent on its definition. ${ }^{3} 1011$ The established causes are inadequate myocardial protection, ${ }^{1213}$ reperfusion injury, ${ }^{14}$ thrombosis of a native coronary artery, and early graft occlusion. Although most infarcts occur during and soon after surgery, others may develop before the operation begins. Prolonged preoperative myocardial ischaemia may be a contributory factor in such patients.

Requests for reprints to Dr H Yousif, Department of Medicine, Russells Hall Hospital, Dudley, West Midlands DY1 2HQ.

Accepted for publication 26 January 1987
This study was designed to investigate the frequency of preoperative ischaemia, its relation to perioperative infarction, and the effectiveness of isosorbide dinitrate infusion in its control.

\section{Patients and methods}

One hundred patients undergoing coronary artery bypass grafting were studied between 1 October 1983 and 30 September 1984 . They were randomly allocated to either the control (50 patients) or the infusion (50 patients) groups. The two groups were found to be comparable in terms of age, sex, clinical presentation, risk factors, previous myocardial infarction, left ventricular function, the number of diseased coronary vessels, medical treatment, the number of grafts, and the surgical procedure (table 1). Ninety two per cent of the patients had chronic stable angina that was poorly controlled by medical treatment. Only $8 \%$ had unstable angina. 
Table 1 Patient characteristics

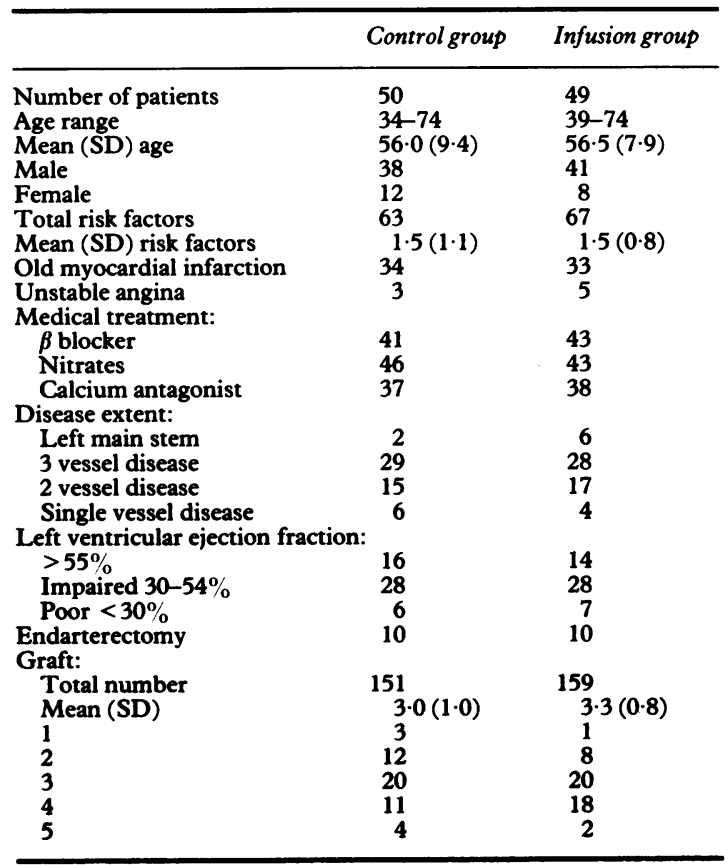

\section{PROTOCOL}

In all patients a standard preoperative routine was followed. This included a 12 hour preoperative fast, except for the continued administration of antianginal and other necessary drugs. Fifty patients were given an intravenous infusion of isosorbide dinitrate (Cedocard, Tillotts) through a battery powered portable syringe pump for 24 hours before operation. The dose was adjusted to a maximum of $15 \mathrm{mg} /$ hour to maintain a systolic blood pressure of at least $90 \mathrm{~mm} \mathrm{Hg}$. There were no untoward side effects but in three patients on a small dose of isosorbide dinitrate the blood pressure dropped during sleep. In these patients the infusion was interrupted at night and resumed in the morning.

The standard cardiopulmonary bypass procedure was used with a flow rate of $2.41 / \mathrm{min}$, systemic hypothermia to $27^{\circ} \mathrm{C}$, and cold potassium cardioplegia. A small number of patients required additional topical cardiac cooling. The aortic cross clamping time averaged 20 minutes with an additional 10 minutes for each graft and each endarterectomy procedure. On average the perfusion time was 15 minutes longer than the clamping time. An average of 3.2 grafts was placed per patient and $80 \%$ of the patients in each group were operated on by the same surgeon.
DETECTION OF ACUTE MYOCARDIAL ISCHAEMIA

In 33 control patients and 34 infusion patients two channel continuous Holter electrocardiographic monitoring with a frequency modulated (Medilog 2, Oxford Instruments) recorder was started 24 hours before surgery and continued until the last possible moment before surgery, including the period of anaesthetic induction. (These two subgroups were also closely comparable in relation to those variables examined in the control and infusion groups.) The recordings were initially examined by visual inspection to detect the presence of transient reversible ST shifts ( $>0 \cdot 1 \mathrm{mV}$ horizontal or downsloping ST segment depression, indicating acute myocardial ischaemia). Automatic computer analysis was performed on the positive tapes to give a continuous plot of heart rate, ST segment negative area, and level of the ST segment $80 \mathrm{~ms}$ after the J point. In addition, the duration of each ischaemic episode, the total number of episodes, and the total duration of ischaemia were also calculated. The 24 hour distribution of ischaemic attacks and their relation to the time of operation were noted.

\section{DETECTION OF ACUTE MYOCARDIAL INFARCTION \\ Electrocardiogram}

Twelve lead electrocardiograms were recorded before operation, immediately after operation, and again on the first, third, fifth, and tenth days after operation. The development of new abnormal $Q$ waves in at least two leads was regarded as diagnostic of acute myocardial infarction.

\section{Creatine kinase}

Venous blood $(10 \mathrm{ml})$ was taken 24 hours before operation, immediately after operation, and one hour and 21 hours after operation for estimation of total creatine kinase and creatine kinase MB. Total creatine kinase activity in serum was measured at $37^{\circ} \mathrm{C}$ in the presence of $\mathrm{N}$-acetyl cysteine by means of kits (Smith Kline Instruments $\mathrm{Co}$ ) and a Clinicon Corona Analyser. The reagents conform to the Scandinavian recommended method for the estimation of creatine kinase.

Creatine kinase $\mathrm{MB}$ was measured by a $\mathrm{N}$-acetyl cysteine-activated ultraviolet system kit (Boehringer Mannheim). The method is based on the immunoinhibition of creatine kinase $M$ subunit activity followed by estimation of the remaining creatine kinase activity. We confirmed that residual activity was due to creatine kinase $M B$, and not to the $B B$ isoenzyme by cellulose acetate electrophoresis. A creatine kinase $\mathrm{MB}$ activity of $750 \mathrm{IU} / 1$ was considered to be diagnostic of myocardial infarction in 

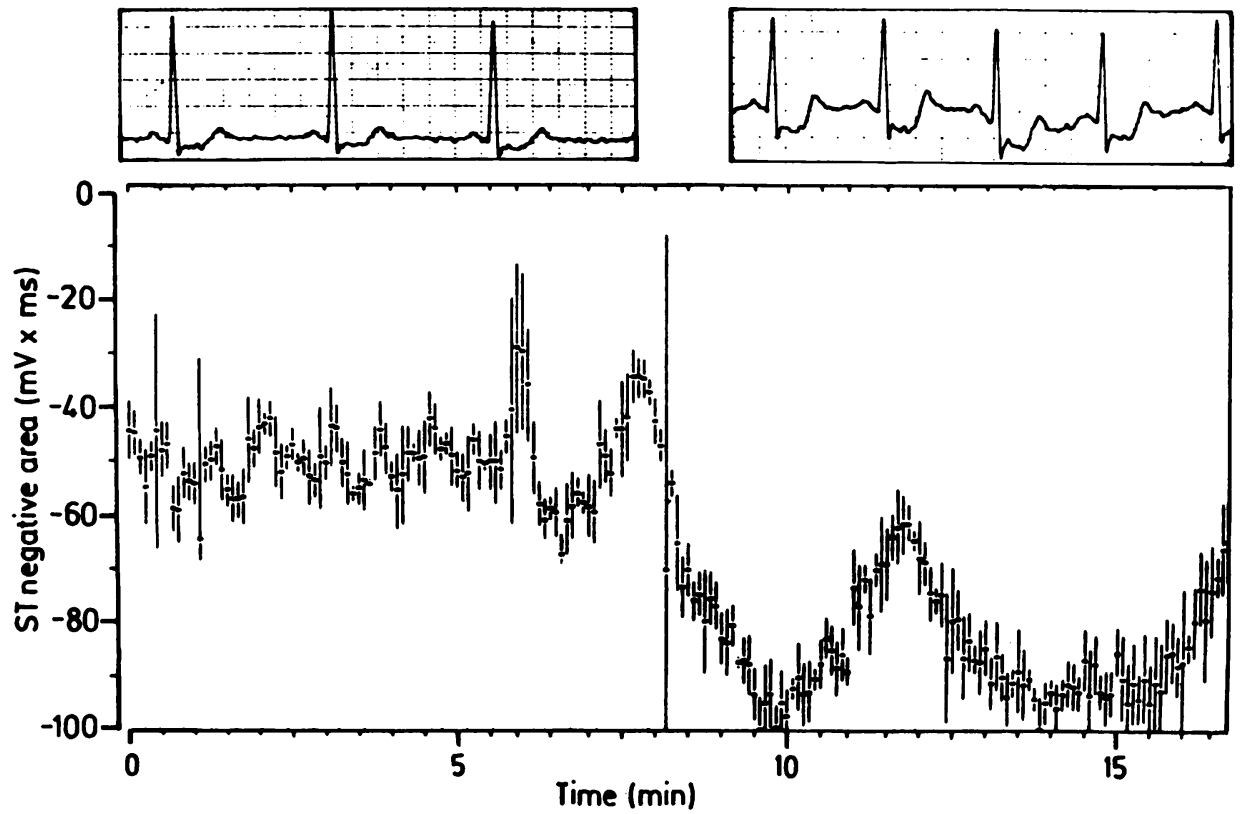

Fig 1 Part of the original ST segment plot (ST negative area) of the patient with severe preoperative myocardial ischaemia who sustained a perioperative infarction.

cases with equivocal electrocardiographic changes and in those (two patients) with left bundle branch block.

\section{Results}

\section{ACUTE MYOCARDIAL ISCHAEMIA}

There were episodes of transient ST segment depression diagnostic of myocardial ischaemia in six $(18 \%)$ of the 33 patients in the control group and in none of the 34 infusion patients. There was a total of 24 transient ischaemic episodes, varying from five to
27 minutes in duration. The total duration of ischaemia was 329 minutes, varying between five and 110 minutes per patient. A patient who had 110 minutes of preoperative ischaemia (fig 1 ) died immediately after operation. The creatine kinase $\mathrm{MB}$ activity of that patient one hour before operation was normal; however, acute infarction was found at necropsy.

The myocardial ischaemic attacks were distributed throughout the 24 hour period, but they tended to cluster between the hours of five and nine in the morning (fig 2) and to increase in the few hours

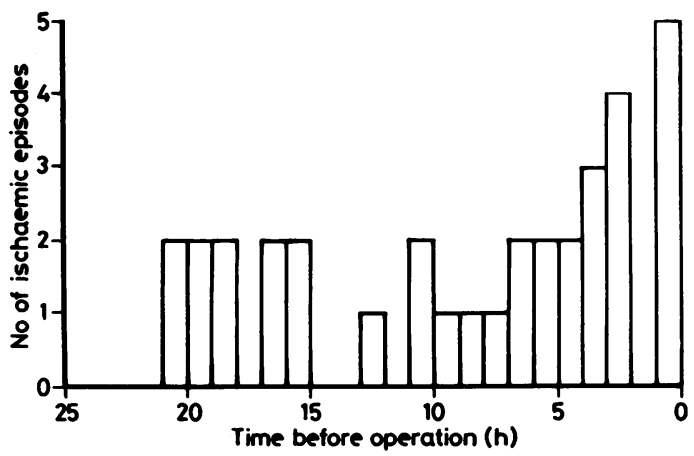

Fig 3 Distribution of the total number of attacks of acute myocardial ischaemia in six control patients during the 24 hour period preceding operation.
Fig 2 Diurnal distribution of the total number of attacks of acute myocardial ischaemia in six control patients. 
immediately preceding surgery, including the induction of anaesthesia (fig 3). The total duration of myocardial ischaemia during the first 21 hours was 192 minutes, rising to 137 minutes during the last three hours preceding surgery.

\section{PERIOPERATIVE ACUTE MYOCARDIAL \\ INFARCTION}

Twenty patients $(20 \%)$ sustained a perioperative myocardial infarction, and the electrocardiograms showed that there were two distinct electrocardiographic patterns of myocardial infarction: $(a)$ the typical pattern where the appearance of convex ST segment elevation was usually followed $(>12.0$ h) later by new $Q$ waves; (b) the atypical pattern, where $Q$ waves appeared much earlier $(<6 \mathrm{~h})$ and without preceding ST segment elevation.

Symes et al showed that pattern (a) is caused by native coronary artery or graft occlusion (occlusive infarction), whereas pattern $(b)$ occurs in the absence of vascular occlusion and may be caused by reperfusion injury (reperfusion infarction). ${ }^{14}$ Fourteen infarcts occurred within six hours of operation and can be considered as intraoperative events; half of

Table 2 Relation of perioperative acute myocardial infarction to preoperative and operative factors

\begin{tabular}{|c|c|c|c|c|}
\hline Factor & $\begin{array}{l}\text { No of } \\
\text { patients }\end{array}$ & $\begin{array}{l}\text { No of } \\
\text { infarcts }\end{array}$ & $\%$ & $p$ \\
\hline \multicolumn{5}{|l|}{ Sex: } \\
\hline $\begin{array}{l}\text { Female } \\
\text { Male }\end{array}$ & $\begin{array}{l}20 \\
79\end{array}$ & $\begin{array}{r}8 \\
11\end{array}$ & $\begin{array}{l}40 \\
14\end{array}$ & $<0.05$ \\
\hline \multicolumn{5}{|l|}{ Blood pressure: } \\
\hline Hypertension & 33 & 9 & 28 & \\
\hline No hypertension & 66 & 11 & 17 & \\
\hline Hypertension/males & 24 & 4 & 17 & \\
\hline Hypertension/females & 9 & 5 & 55 & $<0.05$ \\
\hline \multicolumn{5}{|l|}{ Ischaemia: } \\
\hline Preoperative ischaemia & 6 & 2 & 33 & \\
\hline \multicolumn{4}{|l|}{ Angina: } & NS \\
\hline $\begin{array}{l}\text { Angina: } \\
\text { Unstable angina }\end{array}$ & 8 & 5 & $62 \cdot 5$ & \\
\hline Stable angina & 91 & 15 & 16 & $<0.01$ \\
\hline \multicolumn{5}{|l|}{ Number of vessels diseased: } \\
\hline Single & 10 & 1 & 10 & \\
\hline Double & $\begin{array}{l}32 \\
57\end{array}$ & 7 & 22 & NS \\
\hline \multicolumn{5}{|l|}{ Left main stem stenosis: } \\
\hline Present & 8 & 3 & 38 & \\
\hline Absent & 91 & 17 & 19 & NS \\
\hline \multicolumn{5}{|l|}{ Left ventricular function: } \\
\hline Normal $(E F \geqslant 55 \%)$ & 25 & 2 & 8 & \\
\hline Impaired (EF 30-54\%) & 61 & 14 & 23 & $<0.05$ \\
\hline Poer $\quad(E F<30 \%$ & 13 & 5 & 39 & \\
\hline \multicolumn{5}{|l|}{ Aortic clamping time: } \\
\hline$\geqslant 50 \mathrm{~min}$ & 27 & 10 & 37 & \\
\hline$<50 \mathrm{~min}$ & 72 & 10 & 13 & $<0.05$ \\
\hline \multicolumn{5}{|l|}{ Number of grafts: } \\
\hline One or two & 24 & 4 & 17 & \\
\hline Three & 40 & 8 & 20 & NS \\
\hline \multirow{2}{*}{\multicolumn{5}{|c|}{ Conjunctive endarterectomy: }} \\
\hline & & & & \\
\hline Present & 20 & 8 & 40 & \\
\hline Absent & 79 & 12 & 15 & $<0.05$ \\
\hline
\end{tabular}

EF, ejection fraction. these were typical (occlusion) and half were atypical (reperfusion). Six patients with reperfusion infarction had suffered previous myocardial infarction in the same vascular territory, compared with two who had occlusive infarcts. Table 2 lists the preoperative and operative factors and their relation to infarction.

Three patients $(3 \%)$ died, all of acute perioperative infarction of the typical (occlusive) type. Two were in the control group; one of these had suffered prolonged preoperative ischaemia (fig 1). The patient in the infusion group developed acute myocardial infarction during the second postoperative day, 36 hours after the end of isosorbide dinitrate infusion, and died.

\section{Discussion}

Perioperative acute myocardial infarction is an important factor determining the morbidity and mortality of coronary artery bypass surgery. Recognition and modification of the factors contributing to perioperative infarction may reduce its occurrence.

\section{ACUTE MYOCARDIAL ISCHAEMIA}

Almost one fifth $(18 \%)$ of patients with predominantly stable angina developed appreciable myocardial ischaemia in the hours immediately before operation. Most ischaemic episodes were painless. They increased in frequency and duration as the operation drew near, sometimes appearing for the first time after premedication or during induction of anaesthesia. This increasing tendency for ischaemia to develop might have been related to mounting anxiety in anticipation of surgery or to the haemodynamic changes that accompany induction of anaesthesia. Both factors have been reported to induce myocardial ischaemia. ${ }^{15}$ Declining concentrations of antianginal drugs may have been a contributing factor, although in most of our patients drug treatment was continued up to the time of operation. Irrespective of the mechanism of ischaemia, infusion of isosorbide dinitrate completely prevented the occurrence of acute myocardial ischaemia. Despite the prevention of acute myocardial ischaemia infusion of isosorbide dinitrate had no significant effect on the frequency of perioperative infarction. This finding may be the result of the low frequency of preoperative myocardial ischaemia, which occurred in only six patients in this study of patients with predominantly stable angina. Larger numbers of patients or a higher frequency of preoperative myocardial ischaemia, as might be expected in unstable angina, would be required to demonstrate any significant effect. The multiplicity of mechanisms causing peri- 
operative infarction would also tend to obscure any reduction in the frequency of perioperative infarction related to the prevention of preoperative myocardial ischaemia.

\section{PATHOGENESIS OF PERIOPERATIVE \\ INFARCTION}

Two distinct patterns of evolution of perioperative infarction were observed electrocardiographically. Similar findings have been reported before. ${ }^{14}$ The development of classic ST segment changes evolving into $Q$ wave formation is suggestive of the coagulation necrosis that has been found in association with occluded grafts. The early development of $Q$ waves without previous evolutionary ST changes is compatible with the contraction band necrosis which has been found in association with patent grafts and non-grafted vessels and has been thought to be due to reperfusion injury. Whereas the sudden flux of calcium into cells leads to rapid cellular necrosis in reperfusion injury, the protein denaturation by acidosis and cellular injury by lysosomal enzymes found in coagulation necrosis causes gradual cell death and results in the classic evolutionary changes in the electrocardiogram. Symes et al attributed the majority of intraoperative infarcts to reperfusion injury ${ }^{14}$ but the electrocardiographic pattern in our patients suggests a frequency of approximately $50 \%$. Intraoperative infarcts often occur as an extension of a previously infarcted territory.

Other factors were clearly associated with perioperative infarction in this study. The high frequency in women may be related to the smaller size of their coronary arteries and saphenous veins. The high frequency associated with endarterectomy has been reported by other workers as has the increased frequency in those with unstable angina and poor left ventricular function. ${ }^{16-18}$

Finally, though the incidence of perioperative infarction does not significantly increase with the number of grafts performed, the speed of operation is important. Those patients with technically difficult operations needed prolonged aortic clamping and they had significantly higher infarction rates (table 2).

\section{Conclusion}

A small proportion of patients with predominantly stable angina developed episodes of acute myocardial ischaemia of increasing frequency and duration in the 24 hour period leading up to coronary artery bypass surgery. Although these episodes were abolished by intravenous infusion of isosorbide dinitrate, there was no significant impact on the frequency of perioperative myocardial infarction. This reflects the multifactorial nature of the mechanism of myocardial infarction.

Further study is required to investigate the effect of preoperative ischaemia on perioperative infarction in patients with unstable angina and on postoperative left ventricular function, a determinant of long term prognosis. A further study is in progress in which patient factors, such as endarterectomy, that might obscure the effect of isosorbide dinitrate have been excluded.

We thank Tillotts Laboratories for supplying the isosorbide dinitrate.

\section{References}

1 Rose MR, Glassman E, Isom OW, Spencer FC. Electrocardiographic and serum enzyme changes of myocardial infarction after coronary artery bypass surgery. Am J Cardiol 1974;33:215-9.

2 Sternberg L, Wisneski JA, Ullyot DJ, Gertz EW. Significance of new $Q$ waves after aortocoronary bypass surgery. Circulation 1975;52:1037-44.

3 Brewer DL, Bilbro RH, Bartel AG. Myocardial infarction as a complication of coronary bypass surgery. Circulation 1973;47:58-64.

4 Gray R, Ganz W, Charuzi Y, et al. Morbidity and mortality of perioperative myocardial infarction in coronary bypass surgery: a two year follow-up. Circulation 1978;58(suppl II):11-8.

5 Conley M, McNeer JF, Wagner G, Ross-Duggan J, Harris P, Rosati R. Prognostic significance of myocardial infarction complicating aortocoronary bypass [Abstract]. Circulation 1978;58(suppl II):11-6.

6 Chaitman BR, Alderman EL, Sheffield LT, et al. Use of survival analysis to determine the clinical significance of new $Q$ waves after coronary bypass surgery. Circulation 1983;67:302-9.

7 Assad-Morell JL, Frye RL, Connolly DC, et al. Relation of intraoperative or early postoperative transmural myocardial infarction to patency of aortocoronary bypass grafts and to diseased ungrafted coronary arteries. Am J Cardiol 1975;35:767-73.

8 Fennell WH, Chua KG, Cohen L, et al. Detection, prediction and significance of perioperative myocardial infarction following aorto-coronary bypass. $J$ Thorac Cardiovasc Surg 1979;78:244-53.

9 Oberman A, Cutter G, Kouchoukos N, Allen R, Kitts J, Sheffield T. Survival following perioperative myocardial infarction [Abstract]. Circulation 1980;62 (suppl III):94.

10 McIntosh HD, Garcia JA. The first decade of aortocoronary bypass grafting. 1967-1977. Circulation 1978;57:405-8.

11 Bassan MM, Oatfield R, Hoffman I, Matloff J, Swan HJC. New $Q$ waves after aortocoronary bypass surgery. Unmasking of an old infarction. $N$ Engl $J$ Med 1974;290:349-53.

12 Roe C, Wagner G, Young W, et al. Correlation of creatinine kinase isoenzyme $\mathrm{MB}$ to postoperative 
electrocardiographic diagnosis in patients undergoing coronary artery bypass surgery. Clin Chem 1979;25:93-8.

13 Righetti A, Crawford M, O'Rourke R, et al. Detection of perioperative myocardial damage after coronary artery bypass graft surgery. Circulation 1977;55: 173-8.

14 Symes J, Allard J, Huttner I, et al. Causes of perioperative myocardial infarction: their identification and prevention. Can J Surg 1980;23:438-41.

15 Levinsky L, Lajos $T Z$, Lee AB, Srinivasan V, Schimert G. Refinements in coronary artery surgery contributing to improved survival. Thorac Cardio- vasc Surg 1980;28:102-8.

16 Miller CD, Stinson EB, Oyer PE, et al. Long-term clinical assessment of the efficacy of adjunctive coronary endarterectomy. J Thorac Cardiovasc Surg 1981;81:21-9.

17 Hultgren HN, Pfeifer JF, Angell WW, Lipton MJ, Bilisoly J. Unstable angina: comparison of medical and surgical management. Am J Cardiol 1977; 39:734-74.

18 Baur HR, Peterson TA, Arnar O, Gannon PG, Gobel FL. Predictors of perioperative myocardial infarction in coronary artery operation. Ann Thorac Surg 1981;31:36-44. 